\title{
Buddhist Ethics With Solving the Environmental Problems
}

\author{
Phramaha Sangvech Sricot \\ Mahachulalongkornrajavidyalaya University, Loei Buddhist College, Loei, Thailand \\ Apaporn Bulsathaporn \\ Huachiew Chalermprakiet University, Samut Prakan, Thailand \\ Thaweesak Chooma \\ Mahidol University, Nakhonsawan Campus, Nakhonsawan, Thailand
}

This research aimed to investigate (1) the concept of environmental ethics between the Western and Buddhist ways;

(2) To compare the concept of environmental ethics between the Western and Buddhist ways; (3) To analyze the solving of environmental problems under the Buddhist concept. The results showed that the Buddhism which has had the concept focusing on all living things and being friendly to the nature, having no history of occupying, encroaching and destroying the living things. Nevertheless, giving the values on the environment is still far to the facts of way of life of most humans. However, regarding Buddhist essence that emphasizes that the human as a part of the nature is not conflicted with the ethical values on nature. Complementary to all living things in nature is close to the Dharma practice which starts at itself and knows itself. Dharma practice in Buddhism has assumed to be the individual responsibility on environment itself. Importantly, the Buddhist way of life on environment according to such implication has occurred and really existed in the history of mankind.

Keywords: Buddhist ethics, Environment, Buddhism and ecology

\section{Introduction}

In addition to environment is a near or personal issue to the individuals, directly, it also the community issue. This is not only in the large cities, but in the rural community as well that has faced the environmental problem. Particularly, the problems of chemicals, insecticides, and pesticides. The issue of environment has become a major problem to the society because of the natural environment is a valuable huge resource for humans. It is the origin of food chain, an original source of all aspects of human existence. Whenever it has problems on environment, it will affect to everyone.

Nowadays, the natural environment has faced too much damages whether it will be the forests, mountain, and water sources. This has made the imbalance of nature and loss of biodiversity. Many plant species rapidly disappeared and retained a few animal species. These losses showed apparently and evidence revealed no refusal but it will not be indicated in details, herein ${ }^{1}$.

Phramaha Sangvech Sricot, Ph.D., Assistant Professor, Mahachulalongkornrajavidyalaya University, Loei Buddhist College, Thailand.

Apaporn Bulsathaporn, Lecturer, Department of Environmental Health, Huachiew Chalermprakiet University, Thailand.

Thaweesak Chooma, Lecturer, Mahidol University, Nakhonsawan Campus, Thailand.

1 TheppornMungthani, Environmental ethics under Buddhist ethics in Humanity, Social Science, Faculty of Humanity and Faculty of Social Science, KhonKaen University 19(1) Oct.-Dec. $44: 8$. 
The problems of natural environment is a major obstacle to develop the country achieving the given objectives. The best for solving the environmental problems will need to consider the basic causes of the problems: Human behavior in relation to the environment, a study of culture, behavior and effects on the natural environment in lines of ecology, culture in Thai society, mainly. Beliefs, attitudes, cultural value and tradition are greatly associated with ecological theory. As seen that in the ancient Thai society, most people restricted to the Buddhist ethics, and it well helped maintain in terms of harmonious relationship with the natural environment ${ }^{2}$.

It can be seen that the way to think of the human behavior in the past has resulted in enormous environmental problems as its existence. This has made the thinkers, developers, worldwide, concerned that if it still continue to leave this operation as existed in the past, it will cause an increase of environmental degradation until it becomes a crisis of environment, at last.

With worrying concern in such a situation, it has made review of thinking method and behavior in the past days in order to find out the correct approach as Albert Einstein said, "We shall need a radically new manner of thinking if mankind is to survive". Prawet Vasi said that the world required new ideas in order to survive which is the survival of humankind and the environment ${ }^{3}$.

In the past two decades, there has been tremendous awareness on solving the environmental problems by seeking the solutions with various methods such as using the concepts on environment based economics and technology, and the concept of ecology including introduction of local culture for assisting the environmental management in order to solve the existing problems.

Buddhism is a way existed from the said by the Lord Buddha for 2500 years ago. It is a way of life living aiming at developing, purifying the behaviors, mind and practicing the consciousness and intelligence in order to see the world (environment) and real life. It is a religion generated by the human. It is a religion of humanity and for the way of life living that aiming to solve the problems or the suffering of mankind. Lord Buddha and the followers, spent lives simply and engaged with nature deeply, until knowing and understanding clearly and being aware of the importance of environment. It has seen the relationship between the human and environment, in harmony. This views that the humans naturally have generated both physically which consists of four elements and mentally which has changed the rules of nature, called "the three marks of existence" and living in harmony with nature as the main principle of conditionality (Idhabajata) or The Law of Dependent Origination (Paticca-samuppada), commonly translated as dependent origination or dependent arising, states that all things arise in dependence upon other things or sees the things being followed the process of factor causes, clearly.

The teachings of Buddhism are the matter of Impermanence (Anitjang), Non-self (Anatta), compounded things (Sankhara), which states the sense of uncertainty and the rotation depends on the cycle. It looks like a principle of ecology in matter of natural cycle. The decay of objects that Pardue (1971, p. 9) and Rifkin (1980, p. 21) said bout the rules of Impermanence (Anitjang) and the decay of objects, and the ecology focuses on the limited extent of natural resources that the human require to depend on. Like other living things, Buddhism emphasizes that everything has ended and decomposed, nothing is stable, forever.

\footnotetext{
${ }^{2}$ PaneeNathatecha, Buddhist ethics and Ecological Culture. Printed copy matter, Mor.Por, Por, p. 96.

3 Association for Life and Environment, Operational Plan 21 for Sustainable Development, Brief of main issues of Agenda 21, Ministry of Foreign Affairs, MorPorPhor., p. 11.
} 
The principle of ecology teaches the people to preserve the natural environment. Buddhism principles teaches the people to be kind to nature, and treats the nature as a part of life as Bloom (1972, p. 125) observed that every life has Anatta as the same core or nature, harming another life is as hurting our own because the common point of human life is the nature or core of Anatta.

To understand the real nature or core of Buddhist teachings and the principle of ecology, it will make the humans see the reality of nature that everything relies and depends on each other. The destruction of a nature is to affect the persistence of other things. For example, deforestation has caused several damages thereafter such as floods, landslides and shortages of natural water resources and destructions of wildlife species, etc.

In the timing of serious environmental problem like today, there are many scholars trying to seek the ways for solving such problems, widely, in order to assist finding such solution. A study of concept of environmental management under Buddhism and presentation of environmental management procedures under the Buddhist principles is a way that those are very much interested, in order to understand the approach for dealing with environmental problems which appear in the Buddhist way and to apply such principles as the ways to solve the today's environmental problems. This lets the researcher believes that it will be a way to help solve the existing environmental problems.

\section{Research Objectives}

The research objectives:

(1) To study the concept of environmental ethics between the Western and Buddhist ways;

(2) To compare the concept of environmental ethics between the Western and Buddhist ways;

(3) To analyze the solving of environmental problems under the Buddhist concept.

\section{Scope of Research}

This paper is a documentary research aiming to study and analyze the solving of environmental problems under the Buddhist way. This study contains two scopes: Content and Document as details shown as follows:

\section{Content}

This paper will study the scope of content related to Buddhist ethics in order to contribute to the solution of environmental management: studying the term of environmental ethics, Western theory of environmental ethics, basic concepts of Buddhist ethics, environment under Buddhist way, environment and human behavior, history of Buddhism and the environment in the beginning era, environment and the aim of life, Buddhist ethics and ecology, Buddhism and ecology and so on.

\section{Document}

Searching and studying from the Tripitaka (Thai version) of Mahachulalongkornrajavidyalaya under the cerebration of Her Majesty Queen Sirikit, Buddhist era 2539,CD-Rom of the Tripitaka, Dharmatan volume, a version of Mahamakutrajavidyalaya, printed on the anniversary of 200 years of Chakri dynasty, Ratanakosin. Bangkok: Chalermchanprinting. 2525, which this attakatha data was studied and searched only the Attakatha of PhraSuttanpitaka, books 40-43 (4 volumes), a number of thesis, research papers, documents and academic textbooks and websites related to solving of environmental problems under Buddhist ways. 


\section{Definitions of Research}

- Principle of Buddhist ethics refers to the principle of Sutjadharma or existing fact in nature by determining as the ethics and morality in Buddhism for describing and organizing into the system or applying for well life and social development.

- Environment refers to the things that exists naturally and the human creates surrounding us both visual and un-visual physical characteristics.

- Buddhism and ecology refers to the Buddhist teachings related to the human nature and the nature of environment.

- Western environmental ethics refers to the ethical concept which considers that only the human has moral values, other natural environments without moral values.

\section{Research Methods}

This research is a documentary research, the methods and procedures for conducting research are as follows:

(1) In view of Buddhist ethics, the Book of Tripitaka, a version of Mahachulalongkornrajavidyalaya and major academic textbooks of Buddhist philosophy, both Thailand English versions.

(2) In terms of solving the environmental problems, it is required to study the concepts on the definition of environmental ethics, Western environmental ethics, basic concept of Buddhist ethics, environment based Buddhist environment and human behavior, history of Buddhism and environment in the early era, environment and the aims of life, Buddhist ethics and ecology, Buddhism and ecology. Regarding these documents, the researchers will clarify the figures more clearly in this study by using the academic papers are both in Thailand English that Thai scholars have analyzed, and will be presented as the concept of the Western philosophers in all eras as the above said.

(3) Obtained data collection was studied, analyzed, made understanding and concluded of analysis in order to see the perspective, concepts of Buddhist ethics and how to solve the environmental problems and additional ideas from the researchers. The paper will be answered for the completeness of this research study.

\section{Research Results}

The relationship with the forest and living together in harmony with nature has appeared in the early history of Buddhism as being evident from the history of the Lord Buddha, itself. Mostly, the Lord Buddha spent his life among the nature. Main important events in relation to the Lord Buddha were all occurred among the nature, i.e., the Lord Buddha was born under the Sala tree in the peaceful Lumbini Park situated between the city of Kapilavastu and the city of Devadaha. Now, it is called, Rumminda at Padaria. Lord Buddha has achieved enlightenment under the Si MahaPhottree, where it is now called, Buddhakaya. Lord Buddha provided Buddha's first sermon at Isip-tanamaruekhathaiyawan forest, district of Varanasi where it is now called, Sarnath after the enlightenment for 45 years. Lord Buddha walked by barefoot in order to teach the dharma tasana to individuals. Lord Buddha walked from villages to districts, from districts to small and big cities, and resided in the midst of natural forest, mostly, the place where Lord Buddha spent the stay in a Buddhist monastery during the Buddhist Lent was Chetawan, a garden of Chao Chet and such place Lord 
Buddha stayed mostly were the gardens, forests and mountains, i.e., Veruwan (bamboo garden), Buparama, Mahawan forest, Sisied forest and Makulbanphot, and so on. Finally, even the place for Lord Buddha's nirvana, he chose to pass away under the shaded tree between a pair of Sala trees in the garden of Mallakasat in a city of Kushinagar where it is now called, Kasia. It is seen that Lord Buddha is a great man who taught how to see the importance of natural environment which the humans would assist to each other for remaining in balance.

In relation to Buddhist literatures, it appeared to describe the beauties of nature such as 64 spells ${ }^{4}$ which described the way to a city of Kapilavastu where Karutayi used as a medium to tell Lord Buddha coming into a city of Kapilavastu for teaching his father and relatives. The examples that Karutayi told the spells such as

all trees are now provide flowers and leaves like brown coal leaving their leaves and producing the fruits, these trees look much lighter like the fire flame. All trees are decorated with beautiful flowers and provide clean smell, charming beauty bloom along the way both sides, all birds have beautiful color with peaceful mind like green color, etc., they all sing surrounding and make the happiness with beautiful sounds, oh, Lord who is much diligent, a part of beautiful wording, it is time for coming. (PhraMethidharmaporn, 1998, p. 31)

In view of Buddhism, it is seen that the natural environment is an important factor that contributes the peace in mind. Forests, jungles, rivers and streams are the natural places in proper for practicing the Dharma teachings and causes easy meditation. In the early era, the persons who came and sworn as Buddhist monks after learning meditation practices from Lord Buddha or from their preceptors then sought the places for peaceful meditation. Most were located in the forests and caves, etc. There were many Buddhist words that Lord Buddha advised his followers to practice Dharma in the forests such as the monks should sit, walk and sleep in solitude, keep spirit individually, and be pleased in the forest alone, etc. Practicing the Dharma in solitude was praised by Lord Buddha and announced to praise all monks to act as the example as Phramaha Kasapath era was excellent in ascetic practices which must involve with all forests including residing in the forests as well. The experiences that the Buddhist followers received from the natural environment condition reflected in terms of joyfulness, being pleased to practice Dharma among the nature such as PhraVanavatchath era said "I was satisfied with the stones, blue sky and beautiful clouds, pure stream and cool water, and a number of beetles in the forest". A monk from a town of Rajgir has said, similarly, that regarding clear water, vast cliff covered with moss, having shoal of monkeys and deer and stones, those were all admirable.

All above said, this showed that Buddhism figures the natural environment that providing the spiritual and aesthetic values that are important factors contributing to achieve the peacefulness of mind as a key factor in further enlightenment.

With regard to the natural environment as a supportive factor for the human body and mind, it is considered that the environment is friendly to the human as Lord Buddha has taught more often that personsitting or lying on the shade of the trees should not break the branches of that tree because the one who injures against his friend was an evil person.

In addition to making the deforestation, it is not only the selfishness and violence against the friends, it also provides the destruction of the good environment of the humans as well as destruction of residents of other animals. By the way, in the Buddhist scriptures specify that to cut the trees might destroy the castles of angels of the trees or Rukkatewada as well.

\footnotetext{
${ }^{4}$ PhraMethidharmaporn (PrayoonDharmajitto), Dharma and Conservation of Environment, Bangkok: Dharmasapa Printing, B.E. 2538, p. 31.
} 
Buddhism rejects all types of violence against all kinds of animals. This principle has been made ever since the beginning of announcement of Buddhism in the early era since to blame the Brahmin's sacrifice was not beneficial, but it would give to cause the suffering to all animals and it was the sin to the acted person. In Jatakaand various Buddhist sutras always tried to point out that the animals were all suffering and they avoid the pain like the humans. All animals were friends to the humans which would meet the cycle of being born and died over the suffering in the cycle of birth and death, as being animals, humans with the power of karma. They would make a number of karma and received the consequences of their actions until the fall of cycle of birth and death. By this reason, the human should have compassion towards the animals and things such as cases of Mettasutta, ahirachiksutta or Kanthaparitra, etc. Metta (Kindness) is a Dharma principle which indicates to live together with other animals even some may be toxic to the humans. They should not be killed or hurt, but keep try to seek how to live together in peace by both sides. From the Buddhist history, it is seen that to make the wild and toxic animals being tame with the power of Metta is a way that Lord Buddha has practiced and always brought to teach the followers. It is the method for conserving the animals in order to keep the balance of natural environment under the Buddhist principles, Metta, as the key instrument.

\section{Criticizing Reviews}

It can be seen that the principle of Metta focusing on all kinds of animals are friendly on earth to the humans. In point of Buddhist view from the foundation base that all things are Anatta, having the status equal to in level of ultimate truth of the human, so it is not the center of things, it is different from the Western concept of environmental ethics that keep try to find the theory making the people aware of the importance of animal such as the rights of animals, to conserve some animal species from being extinction. This concept, theoretically, causes the problem whether the animal has the rights or not, if there is, how much and how it is, and when it must face the interests of the human, the rights of animal may be just only in the idea of the theorist.

\section{Suggestions}

Environmental conservation is to emphasize the visual essence on the conservation of natural resources and environment in order to be aware of the need to apply the Dharma principles for conservation benefits as much as possible. This is made by focusing on the study of Thai social context in the ancient Buddhist era in compared with the modern era. It is seen that Lord Buddha and the followers have spent living with nature, never destroyed the ecological system, and provided the disciplines in harmony with nature and environment. Even the people themselves, also see the importance of natural resources and environment. This is also believed that if the earth and the living trees are destroyed, it must be accused and punished. Currently, the natural resources and environment have widely destructed until causing the toxic crisis of global environment. This has made the conservation groups to make the big campaign in such issue.

From this research, it has found the fact that all living things must go on in correspondent and harmony with nature, and the obstacles were revealed as noted below:

(1) Should study for understanding the real Buddhist desires and apply for conservation to be more concrete.

(2) Should prepare the plan for conserving the natural resources and environment by coordination among 
the state and private sectors in order to achieve the objectives as set. In the past, the parties always do not coordinate much better and sometimes the state agencies do not understand the work and cause the problems and lack of knowledge on the right method of conservation. This is not achieved the goal as set.

(3) Should arrange the meeting or seminar for clarifying the problems and obstacles of implementation including having public relations to the public to understand in order to help altogether, both parties.

(4) Should apply the principle of conservation in harmony with Dharma in the same line with Dharma because in the past, Lord Buddha has provided the law for conserving the environment in order to make the regulation for training the body, speech in matter of good conduct and leading to access Dharma as organizing the life for much development.

(5) The government should take much care of facilities in the conservation of natural resources and environment. It may arrange the officials for training the monks to have more knowledge and understanding of conservation and update development.

(6) The government should support and promote the conservers and developers by honoring them as the good role models for society.

If it functions completely, studies and understands deeply and brings it for application for the benefit to the conservation in harmony with Dharma, and the state agencies provide the coordination and cooperation by providing good facilities for activity implementation, it is believed that what the Lord Buddha has ruled regarding the environment for 2540 years, is valuable and useful to Thai and world societies, forever.

\section{References}

Bloom, A. (1972). Buddhism, Nature and the Enviranment. The Eastern Buddhist, 5(1), 115-129.

ChatkumlaKabilasingha et al. (1998). Buddhism for natural conservation. Bangkok: Thammasat University Press.

Pardue, P. A. (1971). Buddhism: Brief Account. New York: Macmillan.

PhraMethidharmaporn. (1995). Dharma and conservation of environment. Bangkok: Dharmasapa.

Rifkin, J. (1980). Entropy: A New World View. New York: Bantam Books. 